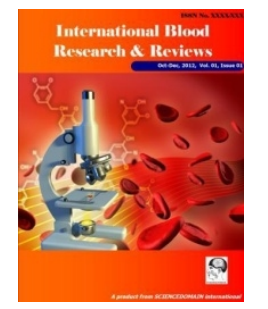

International Blood Research \& Reviews

2(1): 23-28, 2014, Article no. IBRR.2014.003

SCIENCEDOMAIN international

www.sciencedomain.org

\title{
Pure Red Cell Aplasia in a Patient with Cri-Du-Chat
}

\author{
Jing $A i^{1}$, Valeria Visconte ${ }^{1}$, Heesun J. Rogers ${ }^{2}$, Mikkael A. Sekeres ${ }^{3}$ \\ and Ramon V. Tiu ${ }^{1,3^{*}}$ \\ ${ }^{1}$ Department of Translational Hematology and Oncology Research, Taussig Cancer Institute, \\ Cleveland Clinic, Cleveland, $\mathrm{OH}$, USA. \\ ${ }^{2}$ Department of Clinical Pathology, Cleveland Clinic, Cleveland, OH, USA. \\ ${ }^{3}$ Leukemia Program, Department of Hematologic Oncology and Blood Disorders, Taussig \\ Cancer Institute, Cleveland Clinic, Cleveland, OH, USA.
}

\begin{abstract}
Authors' contributions
This work was carried out in collaboration between all authors. Authors JA and RVT collected clinical data and wrote the manuscript; author VV edited the manuscript; author HJR provided bone marrow biopsy images and edited the manuscript; author MAS edited the manuscript and provided beneficial discussion. All authors read and approved the final manuscript.

Case Study

Received $19^{\text {th }}$ September 2013 Accepted $10^{\text {th }}$ October 2013 Published $28^{\text {th }}$ October 2013
\end{abstract}

\section{ABSTRACT}

Background: The Cri-Du-Chat syndrome also known as $5 p$ - syndrome is a rare genetic autosomal disorder with the characteristic deletion of the short arm (p) of chromosome 5. To date, hematologic manifestations characteristic of BM failure have not been linked to this syndrome.

Aims: To evaluate the safety and efficacy of cyclosporine to treat pure red cell aplasia in the clinical setting of $5 p$ - syndrome.

Presentation of Case: We report here a patient with $5 p$ - syndrome who subsequently developed idiopathic pure red cell aplasia. He was treated with cyclosporine $1 \mathrm{mg} / \mathrm{kg}$ twice a day, and achieved a complete remission, with no toxicities.

Conclusion: This case suggests that cyclosporine can be used safely and effectively in such clinical scenario.

*Corresponding author: E-mail: tiur@ccf.org; 
Keywords: Cri-Du-chat syndrome; pure red cell aplasia; cyclosporine.

\section{INTRODUCTION}

The Cri-Du-Chat (cat cry) syndrome was first described by Lejeune et al. in 1963 [1]. It is a rare genetic autosomal disorder with an estimated prevalence of about 1 in 15,000 to 50,000 live-births [1]. This syndrome is also known as monosomy $5 p$ due to the characteristic deletion of the short arm ( $p$ ) of the chromosome 5. The size of the deletion ranges from 5 to $40 \mathrm{Mb}$ [2] encompassing the entire short arm up to the region $5 \mathrm{p} 15$ [3]. It is believed that a loss of multiple genes located on the $p$ arm genetically predispose these patients to the disease, specifically the loss of the regions $5 p 15.2$ and $5 p 15.33$ containing two genes, CTNN2 (catenin, cadherin-associated protein, delta 2) and TERT (telomerase reverse transcriptase). Mutations in TERT are a risk factor for development of bone marrow (BM) failure especially aplastic anemia [4]. Moreover, this gene might be important in the growth and development of the neuronal cells and their haploinsufficiency might cause the cognitive deficits observed in patients with Cri-Du-Chat [5]. The clinical features are low birth weight, distinct craniofacial dysmorphism (such as microcephaly, round face, large nasal bridge, hypertelorism, epicanthal folds, downward slanting palpebral fissures, down-turned corners of the mouth, or micrognathia), the typical high-pitched cry, malformations with cardiac, neurological and renal abnormalities, and severe psychomotor and mental retardation [1]. In addition, the severity of the disease seems to increase proportionally with the size of the genetic deletion. Despite the link between TERT mutation and aplastia anemia, hematologic manifestations characteristic of BM failure conditions have not been linked to this syndrome.

\section{PRESENTATION OF CASE}

Here we present a 21 year old Caucasian male with a history of Cri-Du-Chat syndrome (circular 5 chromosome instead of the typical $5 p$ deletion) who later developed pure red cell aplasia (PRCA). At age of 12, the patient manifested recurrent seizures, for which he received valproic acid as prophylaxis for 8 years but was switched to lamotrigine due to toxicity concerns. He developed progressive fatigue and pallor 3 months later. A complete blood cell test showed severe anemia with hemoglobin $(\mathrm{Hgb})$ levels of $3.5 \mathrm{~g} / \mathrm{dL}$, mean corpuscular volume of $95 \mathrm{fL}$. He was admitted to Robinson Memorial Hospital (Ravenna, Ohio) and received RBC transfusion. Further work-ups showed normal haptoglobin and lactate dehydrogenase, and negative parvovirus-B19 titers (IgG and IgM). No viral/ autoimmune disorders were detected as shown by the negativity for HIV, hepatitis, and antinuclear antibodies. No evidence of bleeding. Due to concerns of drug-related hematologic toxicity, Lamotrigine was discontinued and Lacosamide was started. $\mathrm{He}$ remained transfusion dependent despite the weekly subcutaneous administration of Procrit $(40,000$ up to 60,000 units). BM examination (Fig. 1) showed a normocellular marrow with marked erythroid hypoplasia and maturation arrest, normal granulocytic maturation and megakaryopoiesis, and adequate BM iron stores. Mild plasmacytosis (5-10\%) which appeared polytypic was also seen. Flow cytometry of the BM cells showed no evidence of a lymphoproliferative disorder or increased blasts. No palpable lymphadenopathy or hepatosplenomegaly is present. Conventional cytogenetic analysis revealed a ring chromosome 5 with a minimal loss of the terminal portions of the short and long arms $(46, \mathrm{XY}, \mathrm{r}(5)(\mathrm{p} 15.3 \mathrm{q} 35))$ consistent with his underlying Cri-Du-Chat syndrome. Fluorescence in-situ hybridization showed no evidence of other chromosomal abnormalities like -5q, -7q, $20 \mathrm{q}$, or +8 . Viral inclusions are not seen, chromogenic in-situ hybridization for Epstein-Barr Virus-encoded RNA (EBER) was negative. Past medical/surgical history includes recurrent 
aspiration pneumonia, PEG tube placement (at age of 3 ), percutaneous hamstring lengthening (at age of 7), and placement of bone-attached hearing aid (at age of 10). His activity of daily living is entirely dependent on his caregiver. There is no history of exposure to toxic chemicals or radiation, smoking, alcohol, or illicit drugs. His nutrition and medication (Lacosamide) are largely given through PEG tube. Chart review shows that autoimmune diseases affected his genealogical pedigree. Indeed the mother has psoriatic arthritis and a maternal uncle had a history of aplastic anemia. Based on his clinical history and hematologic profile, he was diagnosed with idiopathic PRCA and he was started on cyclosporine $1 \mathrm{mg} / \mathrm{kg}$ twice a day which was administrated through a PEG tube. His Hgb before starting treatment was $7.3 \mathrm{~g} / \mathrm{dL}$. The patient tolerates the medication well, and his transfusion requirements slowly improved with only one transfusion occurring within the following 4 months since starting treatment. His Hgb improved to $11.1 \mathrm{~g} / \mathrm{dL}$ at month 2 of treatment. By month 5 , the patient has been in complete hematologic remission ( $\mathrm{Hgb} 13.1$ $\mathrm{g} / \mathrm{dL})$, with the most recent follow-up visit at month $8(\mathrm{Hgb} 16.0 \mathrm{~g} / \mathrm{dL})$.

A

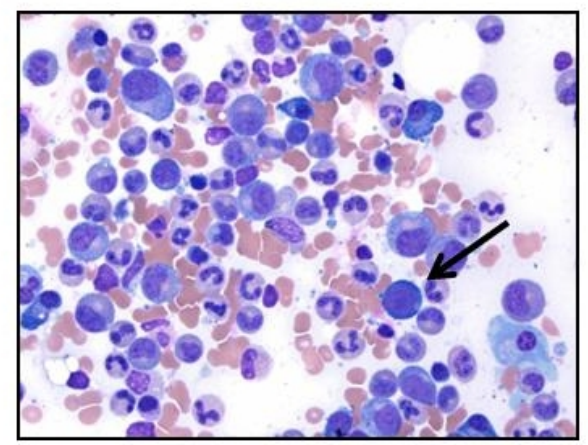

c

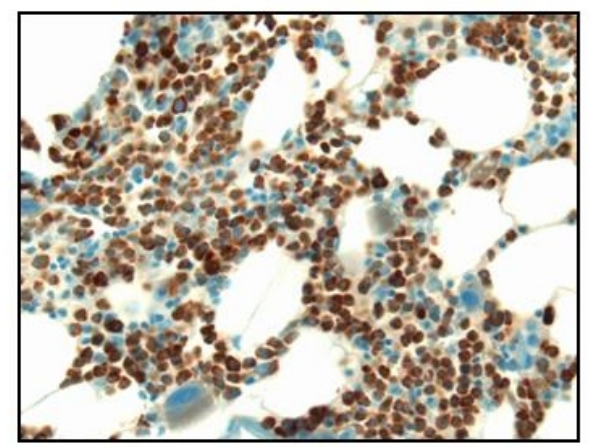

B

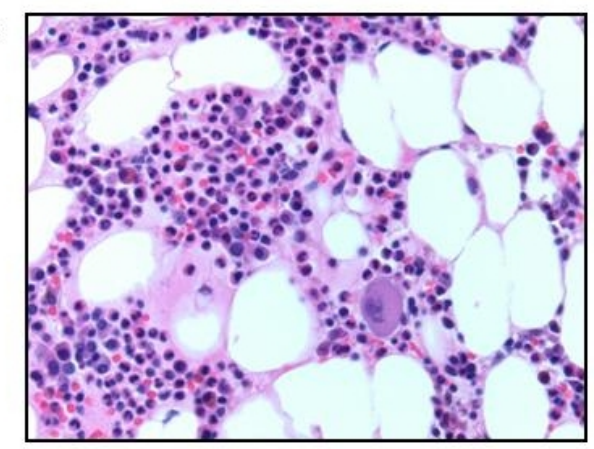

D

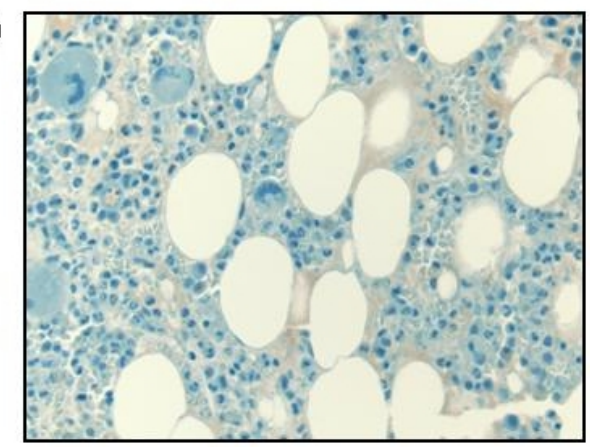

Fig. 1. Bone marrow (BM) aspiration and core biopsy

(A) BM aspiration smear (Wright stain, $x 50$ ) shows predominantly granulocytic cells with normal maturation and no significant dysplasia or increased blasts. There are markedly decreased erythroid precursors, and only rare proerythroblasts (arrow) are noted. (B) BM core biopsy (H\&E, x40) shows normocellularity (50-60\%), normal granulocytic and megakaryocytic maturation and markedly decreased erythroid precursors. (C) Myeloperoxidase immunostain highlights predominantly granulocytic cells in the core biopsy. (D) CD117 immunostain shows no immature cells and erythroid precursors in the core biopsy. 


\section{DISCUSSION}

Acquired PRCA is a rare, generally chronic condition of profound anemia characterized by a severe reduction in erythropoiesis in BM, with other cell lineages usually unaffected. For most adult patients, it is idiopathic, although a number of potential causes have been suggested [6-7], such as medications, infections, malignancies, pregnancy and autoimmune disorders. The potential immunological mechanisms to explain red-cell progenitor destruction have been recently reviewed, including antibody-dependent (as seen in recombinant human erythropoietin-related PRCA and patients receiving ABO-mismatched allogeneic hematopoietic stem cell transplant), T/NK cell-mediated (as seen in PRCA associated with large granular lymphocyte leukemia), and insufficient suppression of autoimmune T-cell populations (as seen in patients with thymoma) [8]. To our best knowledge, there have only been two case reports of patients developing PRCA while receiving Lamotrigine [9]. For patients with PRCA related with pregnancy, medications or certain viral infections, no specific therapy other than transfusion for symptomatic anemia and removal of offending drugs are needed [10-12]. To date, for the remaining patients, especially idiopathic PRCA, there is no standard treatment. The rationale of using immunosuppressive therapy is based on the assumption that the attack on BM is immunemediated. Various regimens have been explored, including steroids [6], cyclophosphamide [6], cyclosporine [6], rituximab [13], daclizumab [14], alemtuzumab [15], and anti-thymocyte globulin [16]. Choice of regimen is largely empiric since there are no randomized clinical trials comparing these given the rarity of the disease, and oftentimes influenced by convenience factors, cost and toxicity profiles. Our patient remained transfusion-dependent despite the discontinuation of Lamotrigine for 6 months, raising the possibility of development of further autoimmune activations after the initial attack from the drug in a patient whose BM progenitors are known to be limited compared to normal individuals [17]. To date, there are no reports that shows that the immune system in patients with Cri-DuChat are compromised, and the pathogenesis of this continued activation of the immune system remain unclear. However, such presumption did provide the basis for a trial of an immunosuppressant. We chose cyclosporine mainly because of its proven safety profile and efficacy in cases of idiopathic PRCA. It has been reported that cyclosporine has a response rate of $65-87 \%$ in otherwise refractory patients [18-20]. Our patient has had an excellent response to cyclosporine with good tolerance. However, caution should be used to taper or discontinue the medication, as relapse could be a common problem after discontinuation [6].

\section{CONCLUSION}

In summary, we reported here the first case of PRCA in a patient with Cri-Du-Chat syndrome who had a complete response and good tolerability to cyclosporine. We think that a genetic predisposition may have been the driver for the development of PRCA in this patient.

\section{CONSENT}

All authors declare that 'written informed consent was obtained from the patient (or other approved parties) for publication of this case report and accompanying images.

\section{ETHICAL APPROVAL}

Not applicable. 


\section{COMPETING INTERESTS}

Authors have declared that no competing interests exist.

\section{REFERENCES}

1. Cerruti Mainardi P. Cri du Chat syndrome. Orphanet J Rare Dis. 2006;1:33.

2. Simmons AD, Goodart SA, Gallardo TD, Overhauser J, Lovett M. Five novel genes from the cri-du-chat critical region isolated by direct selection. Hum Mol Genet. 1995;4(2):295-302.

3. Overhauser J, Huang X, Gersh M, Wilson W, McMahon J, Bengtsson U, et al. Molecular and phenotypic mapping of the short arm of chromosome 5: sublocalization of the critical region for the cri-du-chat syndrome. Hum Mol Genet. 1994;3(2):247-52.

4. Yamaguchi H, Calado RT, Ly H, Kajigaya S, Baerlocher GM, Chanock SJ, et al. Mutations in TERT, the gene for telomerase reverse transcriptase, in aplastic anemia. The New England Journal of Medicine. 2005;352(14):1413-24.

5. Mattson MP and Klapper W. Emerging roles for telomerase in neuronal development and apoptosis. J Neurosci Res. 2001;63(1):1-9.

6. Lacy $M Q$, Kurtin PJ, and Tefferi A. Pure red cell aplasia: association with large granular lymphocyte leukemia and the prognostic value of cytogenetic abnormalities. Blood. 1996;87(7):3000-6.

7. Fisch $\mathrm{P}$, Handgretinger R, and Schaefer HE. Pure red cell aplasia. British Journal of Heamatology. 2000;11(4):1010-22.

8. Sawada K, Hirokawa M, and Fujishima N. Bone Marrow Failure Syndromes Diagnosis and Management of Acquired Pure Red Cell Aplasia. Hematol Oncol Clin North Am. 2009;23(2):249-59.

9. Ikeda $\mathrm{H}$, Ikeda $\mathrm{H}$, Inoue $\mathrm{Y}$. Acute pure red cell aplasia. Rare complication of Lamotrigine treatment. Epilepsia. 2012;53(Suppl.5:91 abstr.).

10. Clark DA, Dessypris EN, and Krantz SB. Studies on pure red cell aplasia. XI. Results of immunosuppressive treatment of 37 patients. Blood. 1984;63(2):277-86.

11. Baker RI, Manoharan A, de Luca E, Begley CG. Pure red cell aplasia of pregnancy: a distinct clinical entity. British Journal of Haematology. 1993;85(3):619-22.

12. Choudry MA, Moffett BK, and Laber DA. Pure red-cell aplasia secondary to pregnancy, characterization of a syndrome. Ann Hematol. 2007;86(4):233-7.

13. Gupta RK, Ezeonyeji AN, Thomas AS, Scully MA, Ehrenstein MR, Isenberg DA. A case of pure red cell aplasia and immune thrombocytopenia complicating systemic lupus erythematosus: response to rituximab and cyclophosphamide. Lupus. 2011;20(14):1547-50.

14. Sloand EM, Olnes MJ, Weinstein B, Wu C, Maciejewski J, Scheinberg P. Long-term follow-up of patients with moderate aplastic anemia and pure red cell aplasia treated with daclizumab. Haematologica. 2010;95(3):382-7.

15. Au WY, Lam CC, Chim CS, Pang AW, Kwong YL. Alemtuzumab induced complete remission of therapy-resistant pure red cell aplasia. Leukemia Research. 2005;29(10):1213-5.

16. Abkowitz JL, Powell JS, Nakamura JM, Kadin ME, Adamson JW. Pure red cell aplasia: response to therapy with anti-thymocyte globulin. American Journal of Hematology. 1986;23(4):363-71.

17. Du HY, Idol R, Robledo S, Ivanovich J, An P, Londono-Vallejo A, et al. Telomerase reverse transcriptase haploinsufficiency and telomere length in individuals with $5 p-$ syndrome. Aging Cell. 2007;6(5):689-97. 
18. Sawada K, Fujishima N, and Hirokawa M. Acquired pure red cell aplasia: updated review of treatment. British Journal of Haematology. 2008;142(4):505-14.

19. Sawada K, Hirokawa M, Fujishima N, Teramura M, Bessho M, Dan K, et al. Long-term outcome of patients with acquired primary idiopathic pure red cell aplasia receiving cyclosporine A. A nationwide cohort study in Japan for the PRCA Collaborative Study Group. Haematologica. 2007;92(8):1021-8.

20. Raghavachar A. Pure red cell aplasia: review of treatment and proposal for a treatment strategy. Blut. 1990;61(2-3):47-51.

(c) 2014 Ai et al.; This is an Open Access article distributed under the terms of the Creative Commons Attribution License (http://creativecommons.org/licenses/by/3.0), which permits unrestricted use, distribution, and reproduction in any medium, provided the original work is properly cited.

Peer-review history:

The peer review history for this paper can be accessed here:

http://www.sciencedomain.org/review-history.php?iid=294\&id=28\&aid=2412 